\title{
Electrospinning Synthesis of Hydroxyapatite Nanofibers Assembled from Nanorods and their Adsorption for Heavy Metal Ions
}

\author{
Yuanyuan Zhou ${ }^{1-3 *}$, Song Li ${ }^{1}$, Dalu Wang ${ }^{4}$, Xi Han ${ }^{1}$ \\ ${ }^{1}$ Institute of Environmental and Municipal Engineering, North China University of Water Resources \\ and Electric Power, Zhengzhou, P.R. China \\ ${ }^{2}$ Henan Engineering Research Center of Water Pollution and Soil Damage Remediation \\ ${ }^{3}$ Henan Key Laboratory of Water Environment Simulation and Treatment \\ ${ }^{4}$ Henan Chemical Industry Research Institute Co. Ltd, Zhengzhou, P.R. China
}

Received: 31 December 2017

Accepted: 7 February 2018

\begin{abstract}
In this work, porous HAP nanofibers assembled from nanorods were developed as potential devices for the treatment of $\mathrm{Cu}(\mathrm{II}), \mathrm{Cd}(\mathrm{II})$, and $\mathrm{Pb}(\mathrm{II})$ contamination of consumable waters. Two steps were employed in the HAP nanofibers fabrication. First, rod-like HAP nanoparticles were synthesized through a chemical pathway from $\mathrm{Ca}\left(\mathrm{NO}_{3}\right)_{2} \cdot 4 \mathrm{H}_{2} \mathrm{O},\left(\mathrm{NH}_{4}\right)_{2} \mathrm{HPO}_{4}$, and polyvinylpyrrolidone (PVP) as a capping agent. The subsequent electrospinning was performed to fabricate the PVP/HAP hybrid nanofibers as precursors to obtain pure HAP nanofibers assembled from nanorods via a calcination process. The effects of PVP dosage on morphology was investigated. And a possible formation mechanism of rod-like HAP was proposed. Then the removal efficiency of porous HAP nanofibers toward $\mathrm{Cu}(\mathrm{II}), \mathrm{Cd}(\mathrm{II})$, and $\mathrm{Pb}(\mathrm{II})$ were evaluated via sorption kinetics and sorption isotherms. Our results proved that the sorption kinetic data were well fitted by the pseudo second-order rate equation, and the adsorption of $\mathrm{Cu}^{2+}, \mathrm{Cd}^{2}$, and $\mathrm{Pb}^{2+}$ ions on HAP nanofibers correlated well with the Langmuir equation as compared to Freundlich isotherm equation under the concentration range studied. These novel porous HAP nanofibers assembled from nanorods promise a feasible advance in the development of new, easy to handle, and low-cost water purifying methods.
\end{abstract}

Keywords: porous, nano-hydroxyapatite, electrospinning, adsorption, heavy-metal

\section{Introduction}

Hydroxyapatite $\left(\mathrm{Ca}_{10}\left(\mathrm{PO}_{4}\right)_{6}(\mathrm{OH})_{2}\right.$, HAP) is a major solid component of the human bone that can be a kind of inorganic biomaterial and used in drug delivery systems;

*e-mail: zhouyuanzy2004@163.com bone grafts; and adsorbents in the treatment of hazardous wastes because of their superior ion exchange ability, high sorption capacity, low water solubility, availability, low cost, and high stability under oxidizing and reducing conditions as well as excellent mechanical properties [1-3]. In the application of water treatment, they are widely used in environmental purification purposes to absorb different metal ions from wastes such as $\mathrm{Cu}(\mathrm{II})$, 
$\mathrm{Pb}(\mathrm{II}), \mathrm{Zn}(\mathrm{II}), \mathrm{Co}(\mathrm{II})$, and $\mathrm{Cd}(\mathrm{II})$ [4-6]. Hence, the key point in its application is how to get the large surface area of HAP to adsorb heavy metal ions. Various methods were used to synthesis nano-sized HAP with high specific surface area and active free valencies such as microwave-assisted, sol-gel, reverse micro emulsion, hydro-thermal, and co-precipitation methods [7-9]. Among these different morphologies of HAP sorbents, porous HAP fibers will exhibit great advantages than other types of HAP materials such as sponges, foams, and conventional powders in wastewater treatment owning to their high sorption efficiency and easy post-treatment. The electrospinning technique has been employed to fabricate HAP nanofibers due to its comparatively low cost and relatively high production rate [10-13], which shows an effective method for fabricating porous HAP nanofibers by calcination process with polymer-HAP hybrid nanofibers as precursors. The aim of this study is to synthesize porous HAP nanofibers assembled from nanorods by electrospinning technique together with a calcination process. The structure and morphology of the HAP rods, HAP/PVP hybrid nanofibers, and pure HAP nanofibers were investigated in detail, and a possible formation mechanism of HAP nanofibers assembled from nanorods is proposed on the basis of the experimental results. The as-prepared HAP nanofibers are explored for the potential application in water treatment, and the removal efficiency of nanofibers toward heavy metal ions were evaluated via sorption kinetics and sorption isotherms. The experimental results exhibit that HAP nanofibers assembled from nanorods have a high adsorption ability for heavy metal ions and selective adsorption activity for $\mathrm{Pb}^{2+}$ ions, thus are promising for the application in wastewater treatment.

\section{Material and Methods}

\section{Materials}

The starting materials used in this work included commercially available calcium nitrate $\left(\mathrm{Ca}\left(\mathrm{NO}_{3}\right)_{2} \cdot 4 \mathrm{H}_{2} \mathrm{O}\right.$, AR, Tianjin Chemical Reagent Factory, China), ammonium phosphate $\left(\left(\mathrm{NH}_{4}\right)_{2} \mathrm{HPO}_{4}, \mathrm{AR}\right.$, Tianjin Chemical Reagent Factory, China), polyvinylpyrrolidone (PVP, $\mathrm{M}=1.3 \times 10^{6}$, Aladdin Reagent), and ammonium hydroxide $\left(\mathrm{NH}_{4} \mathrm{OH}, \mathrm{AR}\right.$, Tianjin Chemical Reagent Factory, China). All chemicals were used without further purification.

\section{Preparation of Samples}

For the preparation of HAP nanorods, $0.042 \mathrm{~mol}$ of $\mathrm{Ca}\left(\mathrm{NO}_{3}\right)_{2} \cdot 4 \mathrm{H}_{2} \mathrm{O}$ was first dissolved completely in $100 \mathrm{~mL}$ of deionized water under continuous stirring. Next, $0.25 \mathrm{~mol}$ of $\left(\mathrm{NH}_{4}\right)_{2} \mathrm{HPO}_{4}, 0.4 \mathrm{~g}$ of PVP, and $10 \mathrm{~mL} \mathrm{NH} \mathrm{NH}_{4} \mathrm{OH}$ were dissolved in $130 \mathrm{~mL}$ of deionized water in turn, and then the above two solutions were uniformly mixed together for 30 minutes. The resulting solution had the $\mathrm{Ca} / \mathrm{P}$ ratio of hydroxyapatite $(\mathrm{Ca} / \mathrm{P}=1.67)$. The reaction system was heated to $85^{\circ} \mathrm{C}$ and then aged for about $2 \mathrm{~h}$. Finally, the product was collected by centrifuging, washed several times with water and ethanol in turn, and air-dried at $60^{\circ} \mathrm{C}$.

$4 \mathrm{wt} \%$ PVP aqueous solution was obtained by dissolving $0.417 \mathrm{~g}$ PVP particles in $10 \mathrm{~mL}$ distilled water with stirring for $3 \mathrm{~h}$. Thereafter, as prepared HAP nanorods and $10 \mathrm{~mL}$ ethanol were dispersed in above PVP aqueous solution and the stirring continued for an additional $3 \mathrm{~h}$. After being vigorously stirred, the solution obtained was fed from a $10 \mathrm{~mL}$ syringe with a 6-gauge blunt-tip needle attached. The syringe was mounted onto a syringe pump (LongerPump LSP02-1B, Hebei, People's Republic of China), and the needle was connected to a high-voltage power supply (Dingtong High Voltage Power Supply, DPS-100 [50 KV/50 w], Dalian, People's Republic of China). Under $17 \mathrm{kV}$ voltage, the fluid jet was injected out at a rate of $1.0 \mathrm{~mL} /$ hour and the resultant nanofibers were collected on aluminum foil, which was put at $15 \mathrm{~cm}$ distance down from the needle. To prepare HAP nanofibers, the HAP/PVP hybrid nanofibers were first prepared as precursors, subsequently dried for $24 \mathrm{~h}$, then heated to $600^{\circ} \mathrm{C}$ for $2 \mathrm{~h}$ to remove the PVP.

\section{Sorption Experimental Procedures}

All the sorption experiments of $\mathrm{Cu}(\mathrm{II}), \mathrm{Cd}(\mathrm{II})$, and $\mathrm{Pb}$ (II) sorption on nanofibers were carried out by batch technique in polyethylene centrifuge tubes under ambient conditions. The materials with different weight ratios of HAP nanofibers and HAP/PVP hybrid nanofibers were prepared as adsorbents for the removal of $\mathrm{Cu}$ (II), $\mathrm{Cd}(\mathrm{II})$, and $\mathrm{Pb}(\mathrm{II})$. Solutions containing heavy metal ions were prepared by dissolving $\mathrm{Pb}\left(\mathrm{NO}_{3}\right)_{2}, \mathrm{Cu}\left(\mathrm{NO}_{3}\right)_{2} \cdot 3 \mathrm{H}_{2} \mathrm{O}$, and $\mathrm{CdCl}_{2} \cdot 2.5 \mathrm{H}_{2} \mathrm{O}$ in deionized water, respectively. Adsorption kinetic experiments were conducted by adding $5 \mathrm{mg}$ of the adsorbents to $20 \mathrm{~mL}$ solution containing heavy metal ions. The initial concentration of heavy metal ion solution was $100 \mathrm{mg} / \mathrm{L}$ for $\mathrm{Pb}^{2+}$, $\mathrm{Cu}^{2+}$, and $\mathrm{Cd}^{2+}$, respectively. The $\mathrm{pH}$ of each solution was adjusted to 6.0 using diluted $\mathrm{NH}_{3} \cdot \mathrm{H}_{2} \mathrm{O}$. The suspensions were stirred at room temperature for $2 \mathrm{~h}$. The supernatant $(1 \mathrm{~mL})$ of the suspension was collected by centrifuging at given time intervals, and the concentration of heavy metal ions in the supernatant was analyzed by an inductively coupled plasma optical emission spectrometer (ICP-OES). In order to study the selective adsorption activity of HAP nanofibers for different heavy metal ions, $5 \mathrm{mg}$ HAP nanofibers was immersed in $20 \mathrm{~mL}$ aqueous solution containing heavy metal ions of $10 \mathrm{mg} / \mathrm{L} \mathrm{Pb}^{2+}, 10 \mathrm{mg} / \mathrm{L} \mathrm{Cu}^{2+}$, and $10 \mathrm{mg} / \mathrm{L} \mathrm{Cd}^{2+}$. The adsorption isotherms were conducted by adding $2 \mathrm{mg}$ HAP nanofibers into $5 \mathrm{~mL}$ aqueous solution containing heavy metal ions, and the other steps are the same as the aforementioned. The initial concentrations of each heavy metal ion solution ranged from 10 to $300 \mathrm{mg} / \mathrm{L}$. The $\mathrm{pH}$ value of each solution was adjusted to 6.0 using diluted $\mathrm{NH}_{3} \cdot \mathrm{H}_{2} \mathrm{O}$. 


\section{Characterization}

Morphological characterization of the HAP nanorods and the prepared nanofibers were performed using a scanning electron microscope (SEM, JSM-5600LV, JEOL, Japan) with a beam voltage at $10 \mathrm{kV}$. All samples were sputter-coated with gold before SEM observation. Transmission electron microscopy (TEM) images of HAP nanorods and the electrospun nanofibers were obtained via transmission electron microscope (JEM-2010; JEOL, Tokyo, Japan). The phase composition and crystallinity of prepared HAP powder was analyzed by x-ray diffraction (XRD, PANalytical X'Pert PRO Netherland) using $\mathrm{Cu} \mathrm{K}_{\alpha}$ radiation, in the range $20^{\circ} \mathrm{C} \sim 60^{\circ} \mathrm{C}$. ICP-OES analysis was taken by an inductively coupled plasma optical emission spectrometer (ICP-OES, JY2000-2, Horiba Scientific, France).

\section{Results and Discussion}

\section{Phase Analysis and Formation Mechanism of HAP Nanorods}

The XRD pattern of HAP powders synthesized by using PVP as a capping agent are shown in Fig. 1, which shows that peak intensity was proportional to the standard spectrum of reference pattern HAP 00-001-1008, and it is also found that there is a single phase of HAP in the product without the diffraction of PVP. However, the diffraction peaks of HAP after $2 \theta \approx 40^{\circ}$ became weak, which indicated that prepared HAP powder was weakly crystallized with HAP as a capping agent, and the grain size was relatively small. Moreover, it was also shown that the effect of PVP on HAP crystal worked on the crystal morphology but not on the phase composition of the product. According to Scherrer's equation, the crystallite size was calculated to be about $30-32 \mathrm{~nm}$ in a-axis direction length and $40-42 \mathrm{~nm}$ in c-axis direction length.

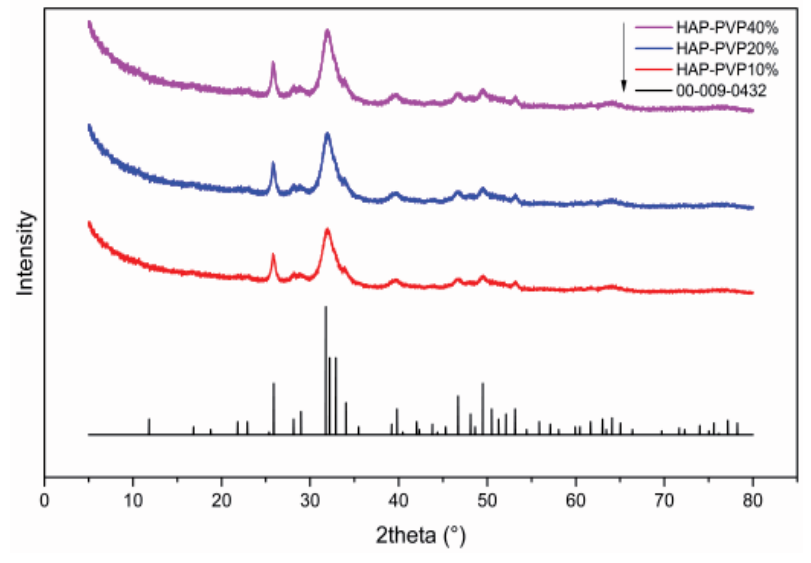

Fig. 1. XRD patterns of HAP powder synthesized with different PVP content.
The other conditions were kept constant and the amount of PVP was altered from $20 \%$ to $40 \%$ to study the effect of PVP amount on the morphology of prepared HAP powder. Fig. 2 shows that the prepared HAP powder is mainly rod-like with a range of $30-50 \mathrm{~nm}$. When the amount of PVP is $20 \%$, the morphology of prepared HAP is relatively uniform, but the size is different. When PVP is added to $40 \%$, HAP is relatively regular, and the final morphology of HAP is short rod-like. As for the role of PVP, it is supposed that PVP acts as a surface-regulating polymer to result in the rod-like morphology of the HAP crystal [14]. The formation mechanism of rod-like HAP crystal with the addition of PVP has been proposed, as shown in Scheme 1, where the whole regulated process of PVP can be divided into three steps. In the first process, a coordination bond was formed with participation of PVP and $\mathrm{Ca}^{2+}$ ions. There is a lactam group with a large polarity in the unit of HAP structure, and the solitary electrons provided by $\mathrm{N}$ and $\mathrm{O}$ atoms may occupy the empty orbit of $\mathrm{Ca}^{2+}$, thereby forming the complex of PVP-Ca ${ }^{2+}$. If the amount of PVP is continually added, what may happen is that both two structural units connect with a $\mathrm{Ca}^{2+}$ ion. The second step is the formation of HAP nuclei under the promotion of the PVP-Ca ${ }^{2+}$ complex. According to some chemical bond theory, the $\mathrm{N}$ and $\mathrm{O}$ atoms in the PVP unit structure have a stronger coordination field than $\mathrm{H}_{2} \mathrm{O}$ molecule. That is to say, the $\mathrm{Ca}^{2+}$ in the $\mathrm{PVP}-\mathrm{Ca}^{2+}$ complex is more likely to form HAP in combination with $\mathrm{HPO}_{4}^{2-}$ and $\mathrm{PO}_{4}^{3-}$. Hence, the complex structure is more likely to form HAP nuclei during the synthesis process. In the third step, PVP was used to regulate the morphology of HAP crystal, and the role of PVP lies in the combination of three effects as follows: spatial, electrostatic, and hydrogen bond. With the increase of PVP content, the configuration of PVP in solution gradually changes from linear and folded linear to spatial reticular structure, and this change of configuration will affect the size and morphology of particles. On the other hand, the PVP adsorbed on the surface of the HAP particles hinders the diffusion and movement of the particles, which hinders the growth of the particles. The two hydroxyl groups in the HAP structural unit can form hydrogen bonds with the carbonyl groups on the nearby PVP chain, which also affects the size and morphology of prepared HAP [15].

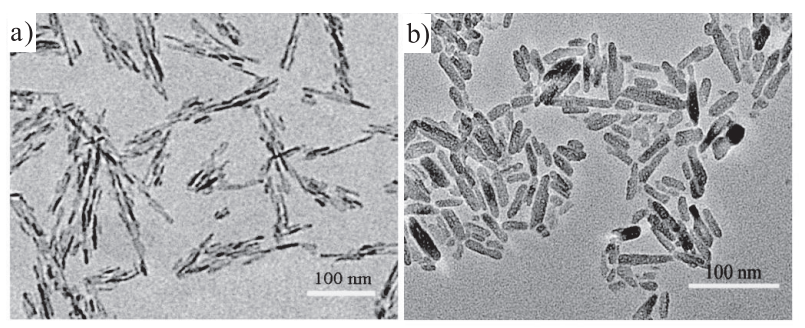

Fig. 2. TEM micrographs of the synthesized HAP powders with different PVP contents for a) $20 \%$ and b) $40 \%$. 

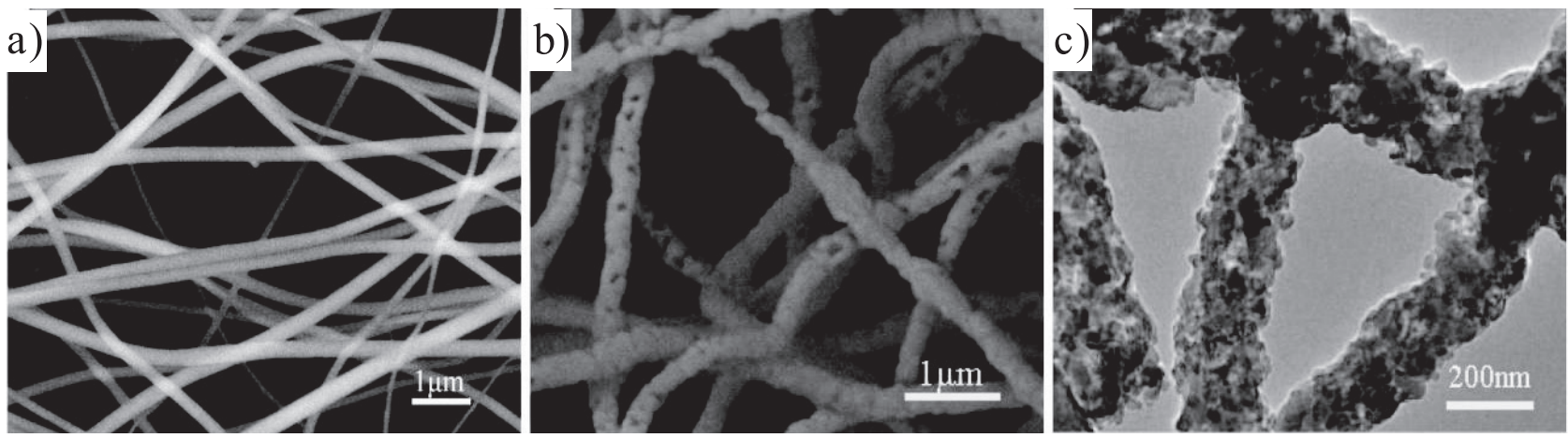

Fig. 3. SEM photographs of a) HAP/PVP nanofibers before calcining, b) HAP nanofibers, and c) TEM photographs of HAP nanofibers.

\section{Morphology Study of HAP Nanofibers}

A thermal treatment route has been designed to prepare single-phase HAP nanofibers using HAP/PVP composite nanofibers as the precursor. Fig. 3 illustrates the SEM photographs of the HAP/PVP hybrid nanofibers and calcined HAP/PVP hybrid nanofibers. Fig. 3a) shows that HAP/PVP hybrid nanofibers with smooth surface are continuous and even, with average diameters of about $500 \mathrm{~nm}$. When the nanofibers were calcined, the shapes of the precursor HAP/PVP composite nanofibers were well preserved. However, the diameter of the single-phase HAP nanofibers decreased due to the decomposition of PVP during the calcination process (Fig. 3b-c). Notably, when the calcination temperature was raised to $600^{\circ} \mathrm{C}$, the complete removal of PVP left lots of pores in the skeleton and formed porous HAP nanofibers (Fig. 3b-c), and each single HAP nanofiber was an assembly of rodlike HAP nanoparticles with diameters of several tens of nanometers, different from the precursor HAP/PVP composite nanofibers. This novel fabrication of singlephase HAP nanofibers assembled from nanorods has potential application as a porous scaffold that can be used in wastewater treatment.

\section{Effect of Different Adsorbents and Adsorbent Doses}

The as-prepared HAP nanofibers assembled from nanorods were explored for potential application in water treatment. The typical heavy metal ions $\mathrm{Cu}^{2+}$, $\mathrm{Cd}^{2+}$, and $\mathrm{Pb}^{2+}$ were chosen for investigation. As a control, the adsorption activities of HAP/PVP hybrid nanofibers for heavy metal ions were also investigated in the adsorption system and the results are shown in Fig. 4. As can be seen from Fig. 4, the sorptions of $\mathrm{Cu}^{2+}$ (Fig. 4a), $\mathrm{Cd}^{2+}$ (Fig. 4b), and $\mathrm{Pb}^{2+}$ (Fig. 4c) on porous HAP nanofibers are all higher than that of HAP/PVP hybrid nanofibers at the same contact time. This result indicated that the adsorption capacities of the HAP/PVP hybrid nanofibers and HAP nanofibers depended primarily on the surface area and the pore size of the adsorbents. The porous HAP nanofibers exhibited the highest efficiency for the removal of $\mathrm{Cu}^{2+}, \mathrm{Cd}^{2+}$, and $\mathrm{Pb}^{2+}$, so it was used
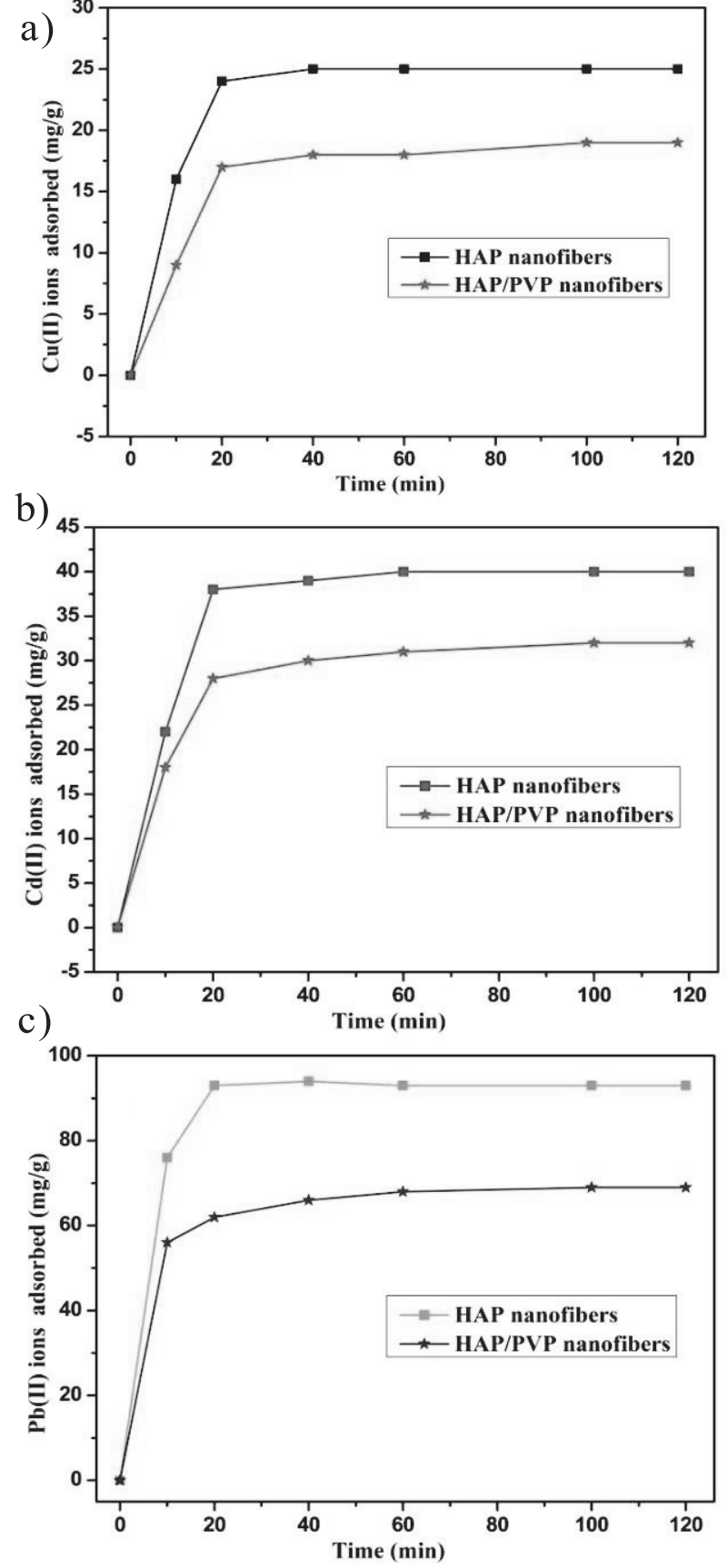

Fig. 4. The sorption of heavy metals on HAP nanofibers and HAP/PVP hybrid nanofibers: a) $\mathrm{Cu}(\mathrm{II})$, b) $\mathrm{Cd}(\mathrm{II})$, and c) $\mathrm{Pb}(\mathrm{II})$. 


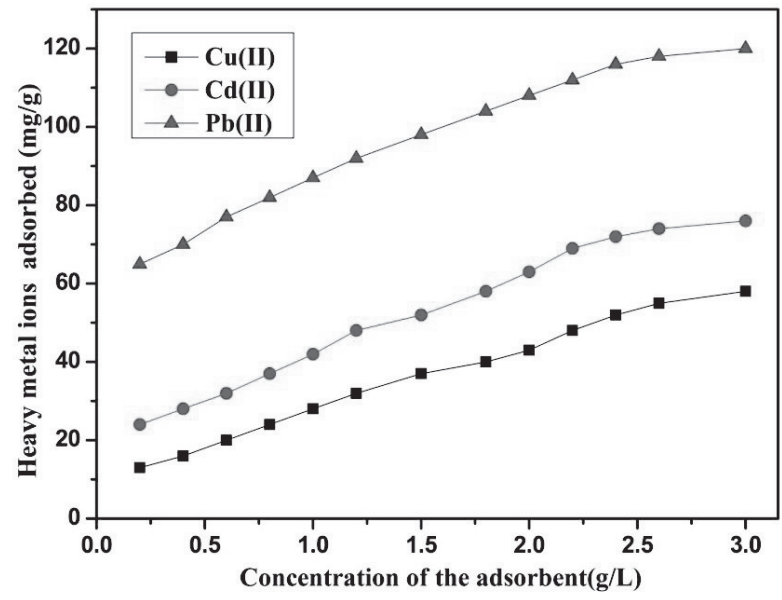

Fig. 5. Adsorbent concentration on the sorption of heavy metal to HAP nanofibers.

for all the remaining adsorption experiments unless otherwise specified.

The adsorption isotherms of porous HAP nanofibers for $\mathrm{Cu}^{2+}, \mathrm{Cd}^{2+}$, and $\mathrm{Pb}^{2+}$ ions were investigated by changing the initial concentrations of metal ions in solutions, and the results are shown in Fig. 5. The experiments indicate that the adsorption amounts of $\mathrm{Cu}^{2+}, \mathrm{Cd}^{2+}$, and $\mathrm{Pb}^{2+}$ ions on the porous HAP nanofibers increased with increasing initial concentrations of metal ions. This can be explained as the initial concentration providing an important driving force to conquer all mass transfer resistances of the metal ions between the aqueous and solid phases. Thus, the higher initial metal ion concentration will increase the adsorption amount. The adsorption amounts of $\mathrm{Cu}^{2+}, \mathrm{Cd}^{2+}$, and $\mathrm{Pb}^{2+}$ ions on the HAP nanofibers were determined to be 93.6, 76.9, and $228.3 \mathrm{mg} / \mathrm{g}$, respectively, at an initial concentration of $300 \mathrm{mg} / \mathrm{L}$. At all initial concentrations, porous HAP nanofibers had a much higher adsorption amount for $\mathrm{Pb}^{2+}$ ions compared with the other two heavy metal ions, indicating that porous HAP nanofibers have a selective adsorption activity for heavy-metal $\mathrm{Pb}^{2+}$ ions. This result is consistent with the adsorption kinetics results.

\section{Sorption Kinetics}

The respective adsorption kinetic of HAP nanofibers for $\mathrm{Cu}^{2+}, \mathrm{Cd}^{2+}$, and $\mathrm{Pb}^{2+}$ was carried out, and the results are presented in Fig. 6. The initial concentration of three heavy metal ions was chosen to be $100 \mathrm{mg} / \mathrm{L}$. The adsorption processes of three different heavy metal ions on the HAP nanofibers almost reached a plateau after $20 \mathrm{~min}$. However, a large amount of $\mathrm{Pb}^{2+}$ ions was adsorbed onto the HAP nanofibers and the whole adsorption process lasted for about $2 \mathrm{~h}$. The adsorption amount of $\mathrm{Cu}^{2+}, \mathrm{Cd}^{2+}$, and $\mathrm{Pb}^{2+}$ ions onto HAP nanofibers at $2 \mathrm{~h}$ was determined to be $23.0,36$, and $93 \mathrm{mg} / \mathrm{g}$, respectively. Moreover, the adsorption efficiencies of $\mathrm{Cu}^{2+}, \mathrm{Cd}^{2+}$, and $\mathrm{Pb}^{2+}$ ions onto the HAP nanofibers at $2 \mathrm{~h}$ were $21.5 \%, 30.7 \%$, and $89.8 \%$, respectively. These

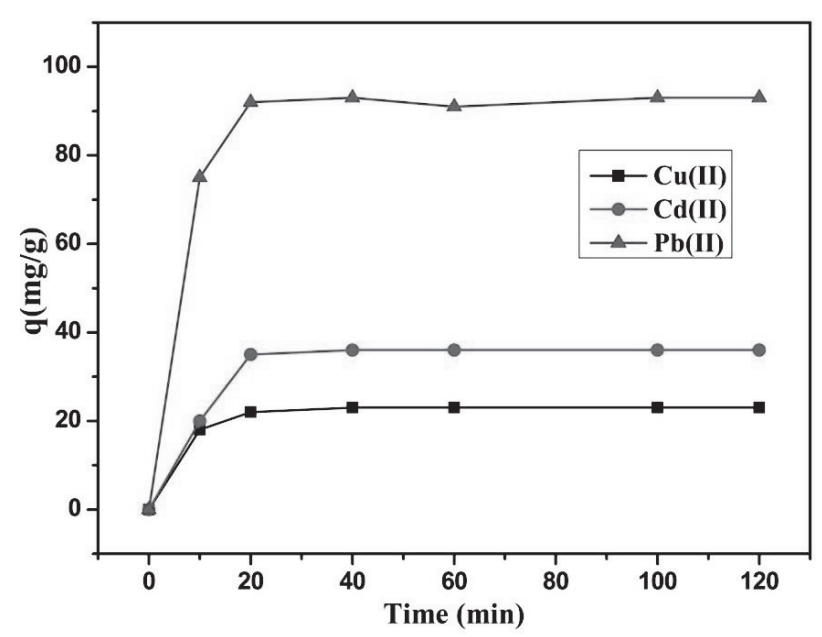

Fig. 6. Respective adsorption kinetics of $\mathrm{Cu}^{2+}, \mathrm{Cd}^{2+}$, and $\mathrm{Pb}^{2+}$ ions on HAP nanofibers.

results indicate that the prepared HAP nanofibers have much higher adsorption activity for $\mathrm{Pb}^{2+}$ ions than those for $\mathrm{Cu}^{2+}$ and $\mathrm{Cd}^{2+}$ ions. It has been reported that the different efficiencies of the adsorption process depend on the electronegativity and ionic radii of the metal ions [16]. Thus, the higher adsorption amount of $\mathrm{Pb}^{2+}$ ions onto the HAP nanofibers was due to its closer electronegativity and ionic radius of $\mathrm{Ca}^{2+}$ ions [17].

The pseudo second-order equation is usually used to describe the kinetics of the adsorption process of metal ions. The pseudo second-order equation is as follows [18]:

$$
\frac{t}{q_{t}}=\frac{1}{k q_{e}{ }^{2}}+\frac{t}{q_{e}}
$$

...where $\mathrm{k}(\mathrm{g} / \mathrm{mg} / \mathrm{min})$ is the second-order rate constant and $\mathrm{q}_{\mathrm{t}}(\mathrm{mg} / \mathrm{g})$ is the adsorption amount of heavy metal

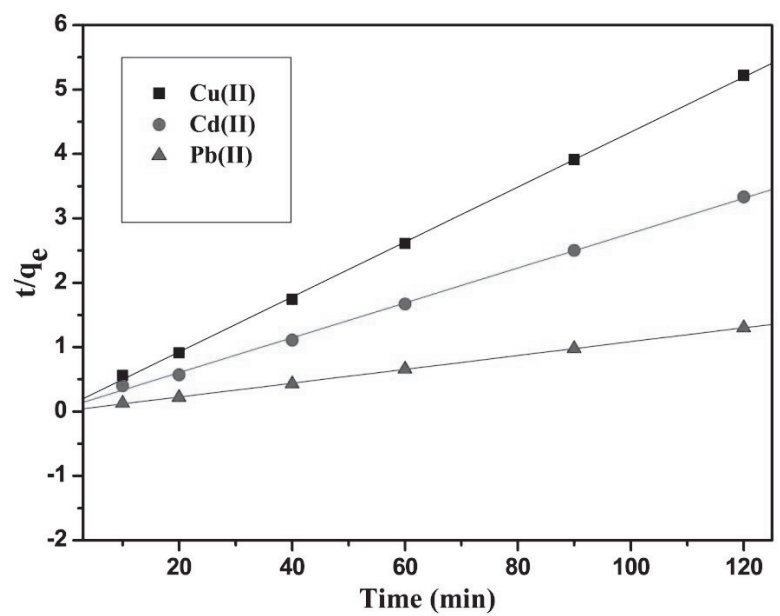

Fig. 7. Pseudo second-order plots of adsorption kinetics of $\mathrm{Cd}^{2+}, \mathrm{Cu}^{2+}$, and $\mathrm{Pb}^{2+}$ ions on HAP nanofibers at an initial concentration of $100 \mathrm{mg} / \mathrm{L}$ and an initial $\mathrm{pH}$ value of 6.0 . 


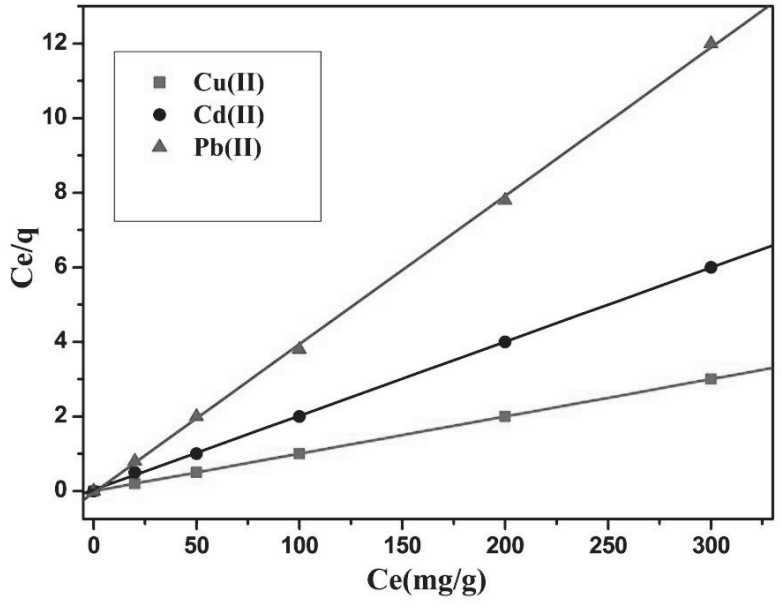

Fig. 8. Langmuir isotherm for the adsorption of heavy metal ions on HAP nanofibers.

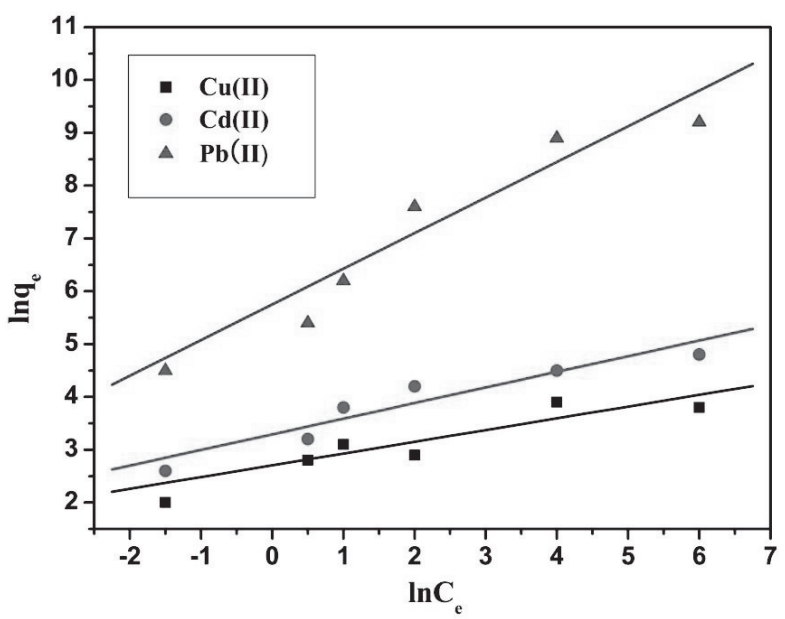

Fig. 9. Freundlich isotherm for the adsorption of heavy metal ions on HAP nanofibers.

ions at any time, and $\mathrm{q}_{\mathrm{e}}$ is the equilibrium adsorption amount of heavy metal ions. Pseudo second-order plots of adsorption kinetics of $\mathrm{Cu}^{2+}, \mathrm{Cd}^{2+}$, and $\mathrm{Pb}^{2+}$ ions on the HAP nanofibers are shown in Fig. 7. A straight line with a slope of $1 / q_{e}$ was obtained by plotting $t / q_{t}$ versus $\mathrm{t}$. The correlation coefficient $\mathrm{R}^{2}$ of adsorption kinetics of $\mathrm{Cu}^{2+}, \mathrm{Cd}^{2+}$, and $\mathrm{Pb}^{2+}$ ions on the HAP nanofibers was determined to be $0.9849,0.9571$, and 0.9461 , respectively.

Table 1. Linear regression coefficient $\left(\mathrm{R}^{2}\right)$ values that correspond to the Langmuir and Freundlich models.

\begin{tabular}{|c|c|c|}
\hline \multirow{2}{*}{ Metal ions } & $\mathrm{R}^{2}$ & $\mathrm{R}^{2}$ \\
\cline { 2 - 3 } & Langmuir & Freundlich \\
\hline $\mathrm{Cu}(\mathrm{II})$ & 0.99989 & 0.87523 \\
\hline $\mathrm{Cd}(\mathrm{II})$ & 0.99987 & 0.92773 \\
\hline $\mathrm{Pb}(\mathrm{II})$ & 0.99977 & 0.89704 \\
\hline
\end{tabular}

The high correlation coefficients indicate that the adsorption kinetics of $\mathrm{Cu}^{2+}, \mathrm{Cd}^{2+}$, and $\mathrm{Pb}^{2+}$ ions on the HAP nanofibers can be described by the second-order equation.

\section{Sorption Isotherms}

Two different models of Langmuir and Freundlich isotherm equations are employed to analyze the sorption isotherms. The Langmuir model is more suitable for single molecule layer adsorption, and this model can be expressed by the following equation [19]:

$$
\frac{c_{e}}{q}=\frac{1}{b q_{m}}+\frac{c_{e}}{q_{m}}
$$

...where $\mathrm{C}_{\mathrm{e}}$ is the equilibrium concentration of metal ions remaining in the solution $(\mathrm{mol} / \mathrm{L}), \mathrm{q}$ is the amount of metal ions adsorbed on per weight unit of solid after equilibrium (mol/g), $\mathrm{q}_{\mathrm{m}}$ is the maximum sorption capacity at complete mono-layer coverage ( $\mathrm{mol} / \mathrm{g}$ ), and $\mathrm{b}$ is a constant associated with the sorption energy (L/ mol ).

The Freundlich model is used to describe a heterogeneous or multilayer adsorption system, and it can be expressed as follows [20]:

$$
\ln q_{e}=\frac{1}{n} \ln c_{e}+\ln K_{F}
$$

...where $\mathrm{n}$ indicates the degree of favorability of the adsorption and $\mathrm{K}_{\mathrm{F}}$ is the isotherm constant for the Freundich model.

Langmuir and Freundlich isotherms for three different heavy metal ions adsorption onto porous HAP nanofibers at $323.15 \mathrm{~K}$ are shown in Figs 8 and 9, respectively, which show that the fitting curves of the two models are similar in shape, and that the two isotherm equations can fit the sorption isotherms well and all the correlation coefficients $\mathrm{R}^{2}>0.87$. The linear regression coefficient $\left(\mathrm{R}^{2}\right)$ values that correspond to the Langmuir and Freundlich models are shown in Table 1. The correlation coefficients $\mathrm{R}^{2}$ values derived from Langmuir mode were slightly larger than that from the Freundlich model, implying that the Langmuir model simulates the experimental data better than the Freundlich model.

\section{Conclusions}

Porous hydroxyapatite nanofibers have been successfully fabricated via calcination process from continuous and even HAP/PVP hybrid electrospun nanofibers, herein the existence of PVP had acted as a capping agent and was used to regulate the nucleation and crystal growth of HAP crystals. The effects of PVP dosage on morphology was investigated. And a possible 
a)
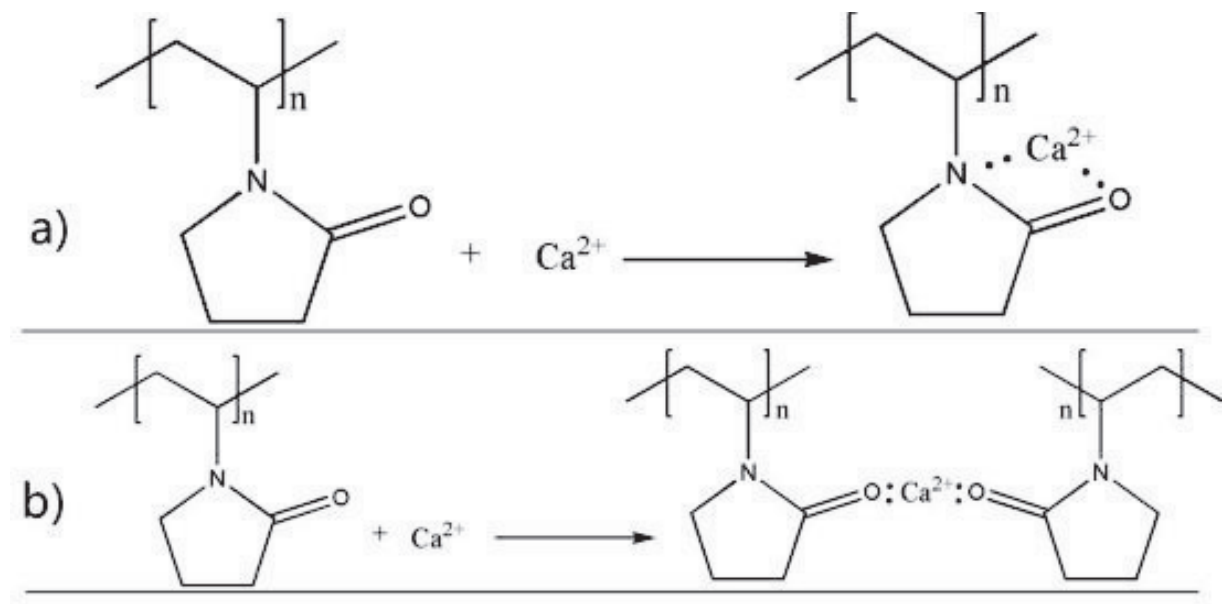

C)
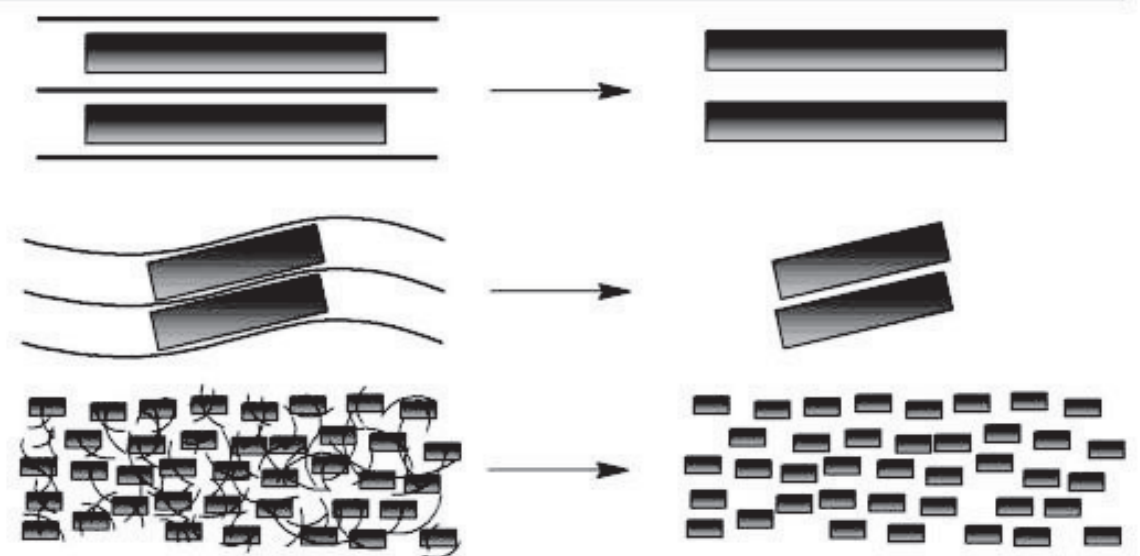

Scheme 1. Formation mechanism of rod-like HAP crystal a) and b): formation of coordination bond, c): transformation of spatial structure with PVP-Ca ${ }^{2+}$.

formation mechanism of rod-like HAP was proposed. The as-prepared HAP nanofibers assembled from nanorods are explored for potential application in the adsorption for typical heavy metal ions such as $\mathrm{Cu}^{2+}$, $\mathrm{Cd}^{2+}$, and $\mathrm{Pb}^{2+}$ from aqueous solution. On the basis of experimental data, porous HAP nanofibers performed a better sorption capability than HAP/PVP hybrid nanofibers under the same experimental conditions. The effect on the sorbent dosage in the sorption system was studied, and the results showed that the adsorption amounts of $\mathrm{Cu}^{2+}, \mathrm{Cd}^{2+}$, and $\mathrm{Pb}^{2+}$ ions on the porous HAP nanofibers increased with increasing initial concentrations of metal ions. The adsorption of $\mathrm{Cu}^{2+}$, $\mathrm{Cd}^{2+}$, and $\mathrm{Pb}^{2+}$ ions on porous HAP nanofibers achieved $50 \%$ and $80 \%$ of the equilibrium adsorption in the first 10 minutes, respectively. The kinetic sorption of $\mathrm{Cu}^{2+}$, $\mathrm{Cd}^{2+}$, and $\mathrm{Pb}^{2+}$ ions on sorbent agreed well with the pseudo second-order model. The comparison of isotherm models illustrates that the Langmuir model described the equilibrium data of $\mathrm{Cu}^{2+}, \mathrm{Cd}^{2+}$, and $\mathrm{Pb}^{2+}$ ions sorption better than the Freundlich model. The results indicate that the porpus HAP nanofibers have a high adsorption capacity for heavy metal ions and high selective adsorption activity for $\mathrm{Pb}^{2+}$ ions, and thus are promising for the application in wastewater treatment.

\section{Acknowledgements}

This work is financially supported by the Key Research Program of the Universities and Colleges in Henan Province (17A150035), and the Talent Research Start-up Fund of North China University of Water Resources and Electric Power (201611).

\section{Conflict of Interest}

The authors declare no conflict of interest.

\section{References}

1. BOANINI E., TORRICELLI P., GAZZANO M., BELLA E.D., FINI M., BIGI A. Combined effect of strontium and zoledronate on hydroxyapatite structure and bone cell responses. Biomaterials, 35 (21), 5619, 2014.

2. CAI R.Z., WANG H.L., CAO M.Y., HAO L.L., ZHAI L.F., JIANG S.T., LI X.J. Synthesis and antimicrobial activity of mesoporous hydroxylapatite/zinc oxide nanofibers. Mater. Des., 87, 17, 2015.

3. CORAMI A., MIGNARDI S., FERRINI V. Cadmium removal from single- and multi metal solutions by sorption on hydroxyapatite. J. Colloid Interface Sci., 317 (2), 402, 2008. 
4. HO Y.S., MCKAY G. Pseudo-second order model for sorption processes. Process Biochem., 34 (5), 451, 1999.

5. KAVITHA M., SUBRAMANIAN R., NARAYANAN R., UDHAYABANU V. Solution combustion synthesis and characterization of strontium substituted hydroxyapatite nanocrystals. Powder Technol., 253, 129, 2014.

6. KIKUCHI M., IKOMA T., ITOH S., MATSUMOTO H.N., KOYAMA Y., TAKAKUDA K., SHINOMIYA K., TANAKA J. Biomimetic synthesis of bone-like nanocomposites using the self-organization mechanism of hydroxyapatite and collagen. J. Compos. Sci. Technol., 64 (6), 819, 2004.

7. LI X., ZHANG S.J., ZHANG X., XIE S.Y., ZHAO G.H., ZHANG L.F. Biocompatibility and physicochemical characteristics of poly(E-caprolactone)/ poly(lactide-coglycolide)/nano-hydroxyapatite composite scaffolds for bone tissue engineering. Mater. Des., 114, 149, 2017.

8. LIN K.L., LIU P.Y., WEI L., ZOU Z.Y., ZHANG W.B., QIAN Y., SHENY H., CHANG J. Strontium substituted hydroxyapatite porous microspheres: surfactant-free hydrothermal synthesis, enhanced biological response and sustained drug release. Chem. Eng. J., 222, 49, 2013.

9. LIUY., SUN Y., CAO C., YANG Y., WU Y.Q., JU D. W., LI F.U. Long-term biodistribution in vivo and toxicity of radioactive/magnetic hydroxyapatite nanorods. Biomaterials, 35 (10), 3348, 2014.

10. MESKI S., ZIANI S., KHIREDDINE H. Removal of lead ions by hydroxyapatite prepared from the egg shell. J. Chem. Eng. Data., 55 (9), 3923, 2010.

11. MISHRA V.K., BHATTACHARJEE B.N., PARKASH O., KUMAR D., RAI S.B. Mg-doped hydroxyapatite nanoplates for biomedical applications: a surfactant assisted microwave synthesis and spectroscopic investigations. J. Alloy. Compd., 614, 283, 2014.
12. PRASAD M., XU H.Y., SAXENA S. Multi-component sorption of $\mathrm{Pb}$ (II), $\mathrm{Cu}$ (II) and $\mathrm{Zn}$ (II) onto low-cost mineral adsorbent. J. Hazard. Mater., 154 (1-3), 221, 2008.

13. RADOICICA K.T., RAICEVIC S. Aqueous Pb sorption by synthetic and natural apatite: kinetics, equilibrium and thermodynamic studies, Chem. Eng. J., 160 (2), 503, 2010.

14. RIEGER K.A., BIRCH N.P., SCHIFFMAN J.D., RIEGER K.A., BIRCH N.P. Designing electrospun nanofiber mats to promote wound healing-a review. J Mater Chem B., 1, 4531, 2013.

15. SHEHA R.R. Sorption behavior of $\mathrm{Zn}(\mathrm{II})$ ions on synthesized hydroxyapatites. J. Colloid Interface Sci., 310 (1), 18, 2007.

16. SMICIKLAS I., DIMOVIC S., PLECAS I., MITRIC M. Removal of $\mathrm{Co}^{2+}$ from aqueous solutions by hydroxyapatite. Water. Res., 40 (12), 2267, 2006.

17. SHUM H.C., BANDYOPADHYAY A., BOSE S., WEITZ D.A. Double emulsion droplets as microreactors for synthesis of mesoporous hydroxyapatite. Chem.Mater., 21 (22), 5548, 2009.

18. SMICIKLAS I., ONJIA A., RAICEVIC S., JANACKOVIC D., MITRIC M. Factors influencing the removal of divalent cations by hydroxyapatite. J. Hazard. Mater., 152 (2), 876, 2008.

19. VILA M., SALCEDO S.S., CICUENDEZB M., BARBA I.I. Novel biopolymer-coated hydroxyapatite foams for removing heavy-metals from polluted water. J. Hazard. Mater., 192 (1), 71, 2011.

20. ZHANG Y.J., LU J.J. A Mild and Efficient Biomimetic Synthesis of Rodlike Hydroxyapatite Particles with a High Aspect Ratio Using Polyvinylpyrrolidone As Capping Agent. Crystal Growth \& Design, 8 (7), 2101, 2008. 